\title{
PENGARUH PENGGUNAAN PENDEKATAN LINGKUNGAN SEBAGAI SUMBER BELAJAR TERHADAP HASIL BELAJAR IPA SISWA KELAS VI SD NEGERI SUMBER
}

\author{
Suroso \\ SD Negeri Sumber Kecamatan Karangan Kabupaten Trenggalek \\ suroso.trenggalek01@gmail.com
}

\begin{abstract}
Abstrak
Penelitian ini bertujuan untuk mengetahui pengaruh pendekatan lingkungan terhadap hasil belajar siswa kelas V pada konsep benda dan sifatnya. Penelitian ini menggunakan penelitian kuantitatif. Menggunakan statistik angka dalam proses penelitian ini. Metode penelitian yang digunakan adalah metode quasi eksperimen. Penelitian ini dilakukan di SD Negeri Sumber Kecamatan Karangan Kabupaten Trenggalek. Sampel dalam penelitian ini terdiri dari dua kelompok, yaitu kelompok eksperimen yang berjumlah 34 siswa dan kelompok kontrol yang juga berjumlah 34 siswa. Kelompok eksperimen adalah kelompok yang diajarkan dengan metode eksperimen verifikasi, sedangkan kelompok kontrol adalah kelompok yang diajarkan dengan metode demonstrasi. Instrumen yang digunakan adalah instrumen tes dalam bentuk pilihan ganda sebanyak 25 soal. Berdasarkan analisis data dengan uji-t yang dilakukan pada taraf kepercayaan $95 \%$ diperoleh hasil $t_{\text {hitung }}>t_{\text {tabel }}(9,26>$ 2,00). Jadi dapat disimpulkan bahwa pendekatan lingkungan berpengaruh terhadap hasil belajar siswa. Sehingga proses pembelajarannya mampu ditangkap langsung oleh siswa mengenai sebuah konsep pembelajaran mengenai materi benda dan sifatnya.
\end{abstract}

Kata Kunci: Pendekatan Lingkungan, Hasil Belajar Siswa.

Abstract(bold, 11, TNR)

This study aims to determine the effect of the environmental approach on the learning outcomes of fifth grade students on the concept of objects and their properties. This research uses quantitative research. Using statistical numbers in this research process. The research method used is a quasi-experimental method. This research was conducted at SD Negeri Sumber Karangan District, Trenggalek Regency. The sample in this study consisted of two groups, namely the experimental group with 34 students and the control group with 34 students. The experimental group is the group that is taught by the verification experimental method, while the control group is the group that is taught by the demonstration method. The instrument used is a test instrument in the form of multiple choice as many as 25 questions. Based on data analysis with t-test conducted at the 95\% confidence level, the results obtained tcount $>$ ttable $(9.26>2.00)$. So it can be concluded that the environmental approach affects student learning outcomes. So 
that the learning process can be captured directly by students about a learning concept regarding material objects and their properties.

Keywords: Environmental Approach, Studets Learning Outcomes.

\section{PENDAHULUAN}

Pendidikan merupakan usaha sadar yang dapat menumbuhkembangkan potensi sumber daya manusia melalui kegiatan pengajaran. Pengajaran bertugas mengarahkan proses pendidikan agar sasaran dari pendidikan dapat tercapai sesuai dengan apa yang diinginkan. Pendidikan bagi bangsa yang sedang membangun seperti bangsa Indonesia saat ini merupakan kebutuhan mutlak yang harus dikembangkan sejalan dengan tuntutan pembangunan secara tahap demi tahap.Guru dapat menggunakan pendekatan pembelajaran yang dapat digunakan di lingkungan dengan melibatkan peserta didik secara penuh sehingga peserta didik memperoleh pengalaman dalam menuju kedewasaan, serta dapat melatih kemandirian peserta didik dapat belajar dari lingkungan kehidupannya Penggunaan pendekatan lingkungan dalam pembelajaran akan mendorong terciptanya suasana belajar yang menyenangkan serta meningkatkan motivasi siswa dalam belajar. Suatu pembelajaran yang terstruktur akan membuat siswa merasa tertantang secara mental. Hal ini akan membuat siswa melanjutkan usahanya sehingga memperoleh hasil belajar yang memuaskan (Fuad Iksan).

IPA merupakan salah satu mata pelajaran yang dipelajari siswa di sekolah dasar.IPA merupakan ilmu yang bersifat empirik dan membahas tentang fakta serta gejala alam.Fakta dan gejala alam tersebut menjadikan pembelajaran IPA tidak hanya verbal tetapi juga faktual. IPA juga berhubungan dengan cara mencari tahu tentang alam secara sistematis. Hal ini menunjukkan bahwa hakikat IPA sebagai proses diperlukan untuk menciptakan pembelajaran IPA yang empirik, faktual dan sistematis dalam rangka melatih kemampuan berpikir logis dan sistematis siswa tentang bagaimana cara produk sains ditemukan. Maka dari itu, pembelajaran IPA sangat perlu diajarkan disekolah dasar aga rsiswa memiliki sikap logis, kritis.

Berdasarkan kenyataan yang ada di SD Negeri Sumber sebagian besar guru hanya mentransfer ilmu pengetahuan saja kepada siswa tanpa berusaha untuk mengaitkan dengan lingkungan siswa dan pengetahuan yang telah dimiliki siswa dari lingkungan disekitarnya dan pengalamannya dengan pengetahuan yang akan dipelajari siswa di sekolah. Dengan demikian, belajar hanya bersifat hafalan saja dan kurang bermakna. Untuk mengatasi 
masalah tersebut dapat dilakukan dengan menggunakan pendekatan lingkungan sebagai sumber belajar sehingga dapat membuat pembelajaran lebih bermakna.

Penggunaan dan pemanfaatan lingkungan dalam pembelajaran merupakan suatu pekerjaan yang tidak mudah. Banyak hal yang harus dipelajari dalam pemanfaatan dan penggunaan agar dapat berhasil menggunakannya, disamping perlu latihan-latihan penggunaan lingkungan dalam pengajaran. Tentunya penggunaan lingkungan ini harus disesuaikan dengan materi pelajaran yang akan disampaikan kepada siswa agar apa yang dipelajarinya dapat dipahami dan dimengerti.

\section{METODE PENELITIAN}

Metode yang dipakai dalam penelitian ini adalah metode eksperimen semu (Quasi Eksperimen). Pada penelitian ini kelompok uji coba (eksperimen) dan kelompok pembanding (kontrol) tidak dipilih secara acak.Kedua kelompok sudah ada sebelumnya.Kelompok pertama adalah kelompok eksperimen yang diberikan perlakuan dengan pendekatan lingkungan dan kelompok kedua adalah kelompok kontrol yang diberikan perlakuan dengan metode konvensionali. Metode ini dipilih karena tujuan utama penelitian ini adalah untuk mengetahui dampak yang ditimbulkan dari suatu perlakuan (treatment).

Desain penelitian yang digunakan yaitu Non-Randomize Control Group Pretest and Posttest Design. Rancangan ini melibatkan dua kelompok, yaitu kelompok eksperimen dan kelompok kontrol. Sebelum diberikan perlakuan pada kedua kelas diberikan pretest. Selanjutnya kelompok eksperimen diberikan perlakuan dengan pembelajaran menggunakan metode pendekatan lingkungan, sedangkan kelompok kontrol diberi perlakuan dengan metode konvensional. Setelah perlakuan, kedua kelas diberikan posttest.

Populasi dalam penelitian ini adalah siswa-siswi SDN Sumber Kecamatan Karangan. Namun penelitian tidak akan mengambil jumlah populasi secara keseluruhan, melainkan hanya mengambil sampel saja, agar subjek yang diteliti tidak terlalubanyak.

Sampel adalah sebagian atau wakil populasi yang diteliti.Bila populasinya besar, peneliti tidak mungkin mempelajarinya semua karena keterbatasan waktu, tenaga, dan dana, maka peneliti dapat menggunakan sampel dari populasi tersebut. Adapun sampel yang diteliti dalam penelitian ini berjumlah 68 siswa, yaitu kelas VA yang terdiri dari 34 siswa sebagai kelas kontrol dan kelas VB yang terdiri dari 34 siswa sebagai kelas eksperimen.

Teknik pengambilan sampel yang digunakan dalam penelitian ini adalah purposive sampling, yaitu mengambil sampel pada kelas yang tersedia tanpa melakukan random sampling. Berdasarkan teknik tersebut, penentuan kelas eksperimen dan kelas kontrol ditentukan dari hasil tes awal (pretest). Hasil pretestyang rata-ratanya lebih tinggi 
dijadikan kelas kontrol sedangkan hasil pretest yang rata-ratanya lebih rendah dijadikan kelas eksperimen yaitu kelas yang diberikan perlakuan (treatment).

Cara yang digunakan dalam pengumpulan data penelitian ini adalah dengan memberikan tes awal(pretest) dan tes akhir (posttest). Pretest adalah tes yang dirancang untuk mengukur kemampuan awal sebelum program pembelajaran dilakukan. Posttest adalah tes yang dirancang untuk mengukur kemampuan akhir setelah program pembelajaran dilakukan.

Instrumen penelitian yang digunakan dalam penelitian ini adalah tes hasil belajar IPA. Tes hasil belajar IPA berupa tes objektif dalam bentuk pilihan ganda dengan 4 alternatif jawabanyaitu A, B, C, dan D pada konsep benda dan sifatnya. Tes disusun berdasarkan indikator yang disesuaikan dengan KTSP, skor yang digunakan pada pilihan ganda adalah bernilai satu (1) untuk jawaban yang benar dan nol (0) untuk jawaban yangsalah.

\section{HASIL PENELITIAN DAN PEMBAHASAN}

Berdasarkan hasil perhitungan pretest dan posttes klelompok eksperoimen dan kelompok kontrol yang terdiri dari 34 siswa diperoleh rekapitulasi data sebagai berikut:

Tabel 1

Rekapitulasi Dara Hasil Pretest dan Posttest

Kelas Eksperimen dan Kelas Kontrol

\begin{tabular}{|l|c|c|c|c|}
\hline \multirow{2}{*}{$\begin{array}{l}\text { Distribusi } \\
\text { Frekuensi }\end{array}$} & \multicolumn{2}{|c|}{ Pretest } & \multicolumn{2}{c|}{ Posttest } \\
\cline { 2 - 5 } & Eksperimen & Kontrol & Eksperimen & Kontrol \\
\hline Nilai & & & & \\
Terendah & 24 & 32 & 68 & 48 \\
\hline $\begin{array}{l}\text { Nilai } \\
\text { Tertinggi }\end{array}$ & 64 & 72 & 92 & 76 \\
\hline Mean & 45,14 & 48,58 & 82,22 & 65,14 \\
\hline Median & 44,5 & 46,28 & 83 & 65,35 \\
\hline Modus & 34 & 43,17 & 88,91 & 61,38 \\
\hline
\end{tabular}

Sebelum melakukan penelitian terhadap kelompokeksperimendan kelompok kontrol, dilakukan pretest untuk mengetahui kemampuan awalsiswa. Dari hasil pretest diketahui rata-rata nilai kelompok eksperimen45,14 dan rata-rata nilai kelompok kontrol 
48,58. Hal ini menunjukkan bahwa kedua kelas tersebut mempunyai kemampuan awal yang tidak jauh berbeda sebelum diberikan perlakukan.

Setelah mengetahui kemampuan awal siswa, selanjutnya adalah memberikan perlakuan terhadap kelas eksperimen dengan pendekatan lingkungan, dan kelas kontrol dengan metode konvensional. Tabel diatas menunjukkan bahwa terjadi perubahan setelah diberikan perlakuan. Perubahan terbesar terjadi pada kelas eksperimen, yaitu terjadinya kenaikan nilairata-rata dari 45,14 menjadi 82,22, yaitu sebesar 37,08. Demikian pula pada kelas kontrol yang mengalami kenaikan nilai rata-rata dari 48,58 menjadi 65,14 yaitu sebesar 16,56. Artinya kenaikan nilai rata-rata setelah perlakuan pada kelas eksperimen lebih tinggi dibandingkan kelaskontrol.

Analisis data pretest kelas eksperimen maupun kelas controlberdasarkan jenjang kognitif ditunjukan pada diagram berikut:

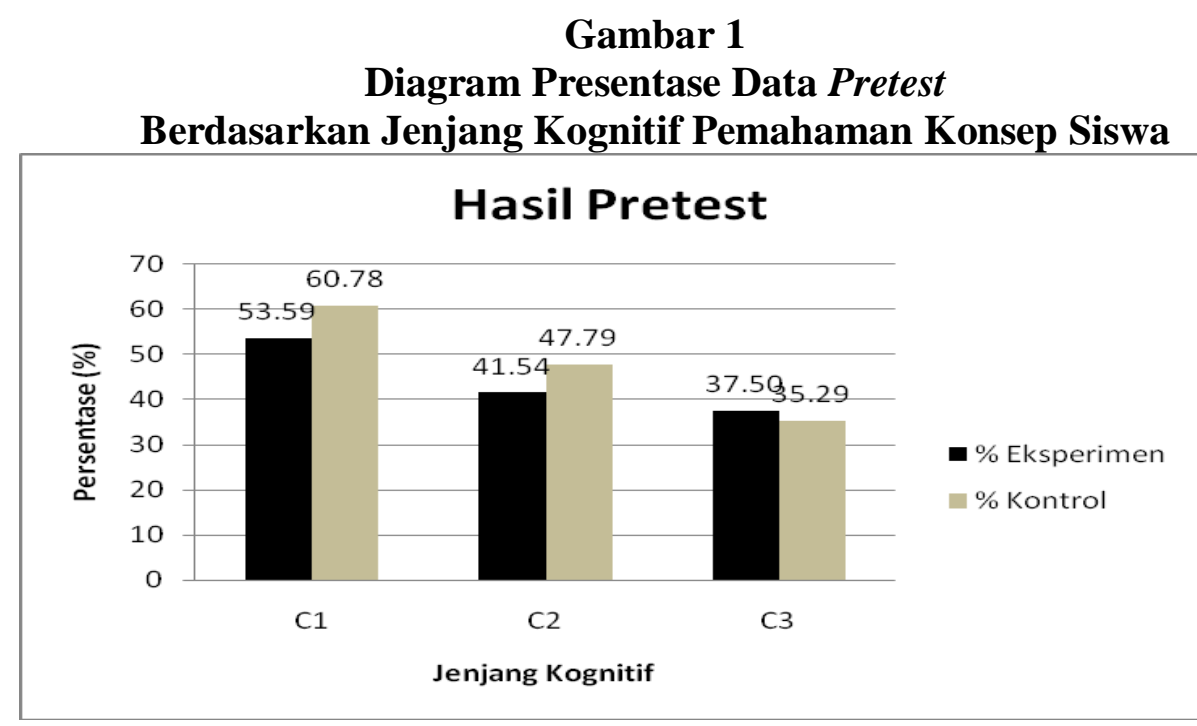

Keterangan:

$\mathrm{C}_{1} \quad$ = Jenjang kognitif tingkat pengetahuan

$\mathrm{C}_{2} \quad$ = Jenjang kognitif tingkatpemahaman

$\mathrm{C}_{3} \quad=$ Jenjang kognitif tingkatpenerapan

Gambar 1.1 menunjukkan persentase pretest kelas eksperimen dan kelas kontrol berdasarkan jenjang kognitif $\mathrm{C}_{1}$ (pengetahuan), $\mathrm{C}_{2}$ (pemahaman), $\mathrm{C}_{3}$ (penerapan). Pada diagram di atas, terlihat bahwa persentase data pretest untuk kelas eksperimen pada jenjang kognitif $\mathrm{C}_{1}, \mathrm{C}_{2}$ terlihat lebihrendahdibandingkan dengan kelas kontrol. Akan tetapi, persentase pada jenjang kognitif $\mathrm{C}_{3}$ kelas eksperimen memperoleh hasil persentase lebih tinggi dibandingkan kelas kontrol. Perbedaan tersebut disebabkan karenamasingmasing kelompok belum diberikan perlakuan sehingga kemampuan siswa tidak merata 
pada semua jenjang pemahaman. Analisis data posttest kelas eksperimen maupun kelas control berdasarkan jenjang kognitif ditunjukan pada diagram berikut:

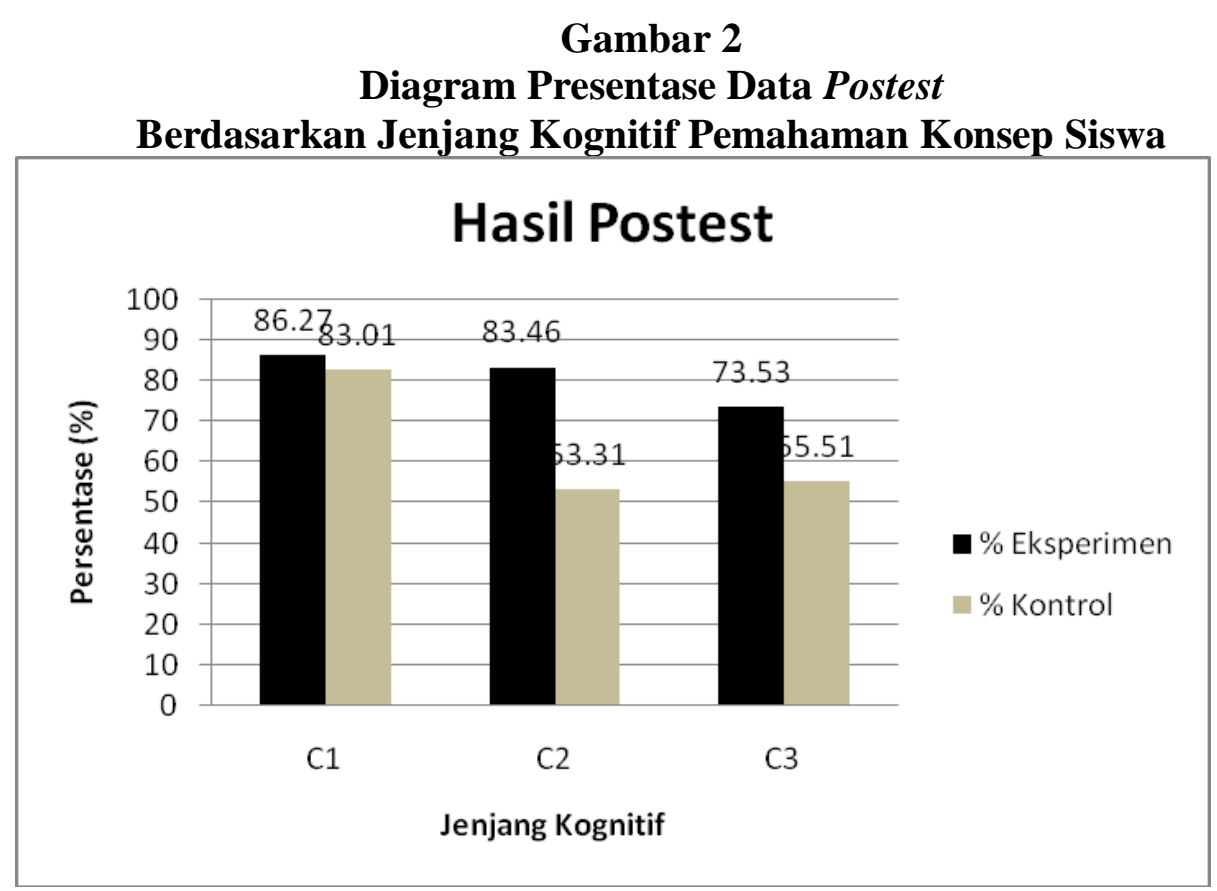

Keterangan:

$\mathrm{C}_{1} \quad$ = Jenjang kognitif tingkat pengetahuan

$\mathrm{C}_{2} \quad=$ Jenjang kognitif tingkatpemahaman

$\mathrm{C}_{3} \quad=$ Jenjang kognitif tingkatpenerapan

Gambar 1.2 menunjukkan persentase postest kelas eksperimendankelas kontrol berdasarkan jenjang kognitif $\mathrm{C}_{1}$ (pengetahuan), $\mathrm{C}_{2}$ (pemahaman), $\mathrm{C}_{3}$ (penerapan). Pada diagram di atas, terlihat bahwa persentase data postest untuk kelas eksperimen disegala jenjang kognitif baik $\mathrm{C}_{1}, \mathrm{C}_{2}$, dan $\mathrm{C}_{3}$ memperoleh hasil lebih tinggi dibandingkan dengan kelas kontrol. Hal ini disebabkan karena perlakuan yang berbeda antara kelas eksperimendengankelas kontrol. Kelas eksperimen yang diberi perlakuan dengan pendekatan lingkungan memperoleh hasil postest yang lebih tinggi dibandingkan dengan kelas kontrol yang diberi perlakuan dengan metode konvensional

Untuk mengetahui lebih jelas perbedaan aspek kognitif mana saja yang mengalami kenaikan secara nyata dapat dilihat pada gambar persentase aspek kognitif dibawahini: 


\section{Gambar 3}

Diagram Presentase Data Pretest dan Postest

Berdasarkan Jenjang Kognitif Pemahaman Konsep Siswa

Kelas Eksperimen dan Kelas Kontrol

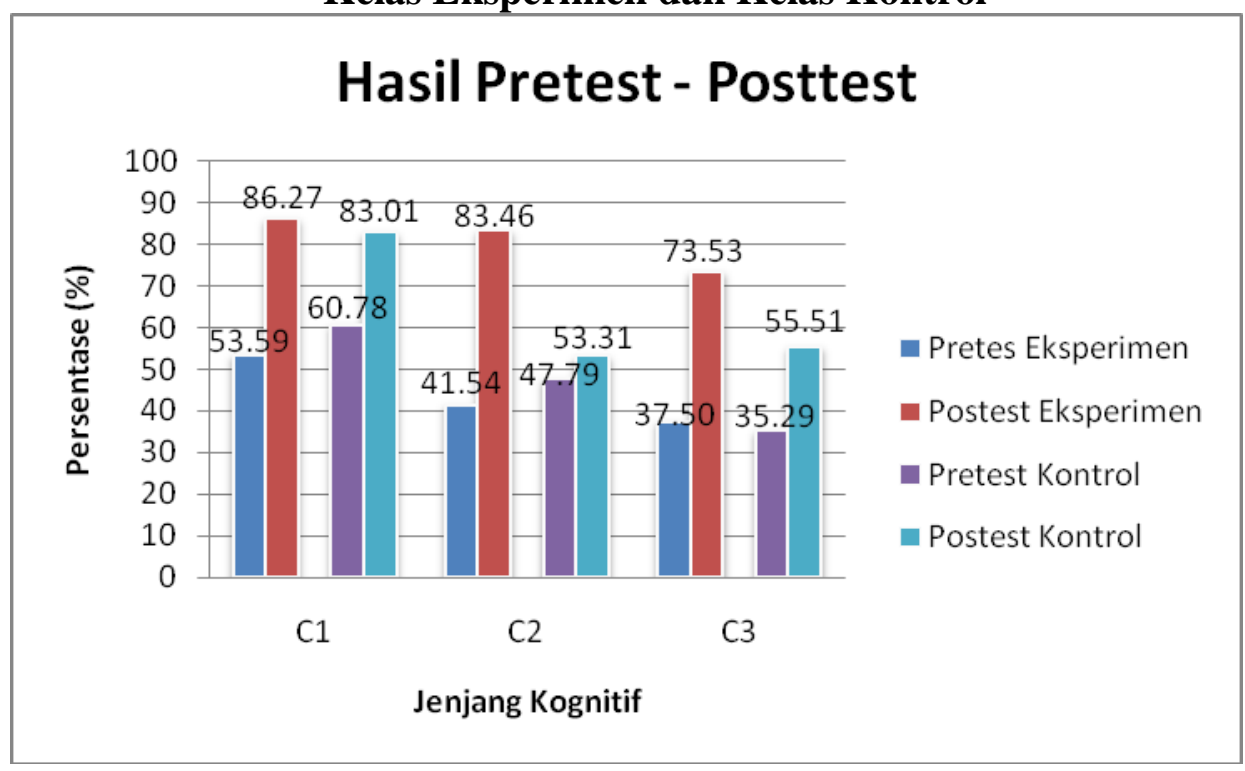

Pada gambar 1.3 di atas diketahui bahwa hasil posttest kedua kelompok mengalami peningkatan. Terlihat bahwa terdapat perbedaan antara kemampuan siswa kelas eksperimen dan kelas kontrol pada hasil pretest dan posttest-nya. Setelah diberikan perlakuan yang berbeda antara kelas eksperimen yang menggunakan pendekatan lingkungan dan kelas kontrol menggunakan metode konvensional, ternyata hasil belajar siswa kelas eksperimen memperoleh hasil tertinggi di setiap jenjang dibandingkan dengan kelas kontrol. Pada jenjang kognitif tingkat $\mathrm{C}_{1}$ hasil yang diperoleh kedua kelompok tidak jauh berbeda, yaitu 86,27 untuk kelas eksperimen dan 83,01 untuk kelas kontrol. Pada jenjang kognitif tingkat $\mathrm{C}_{2}$, dan $\mathrm{C}_{3}$ diperoleh hasil yang jauh berbeda antara kelas ekperimen dan kelas kontrol. Padajenjangkognitif tingkat $C_{2}$ hasil yang diperoleh kelas eksperimen adalah 83,46, sedangkan kelas kontrol adalah 53,31. Kemudian pada jenjang kognitif tingkat $\mathrm{C}_{3}$ hasil yang diperoleh kelas eksperimen adalah 73,53, sedangkan kelas kontrol adalah55,51. 
Hasil uji normalitas pretest dan posttest kedua sampel penelitian dapat dilihat padatabel 2 berikut ini:

\section{Tabel 2}

Hasil Uji Normalitas Pretest-Posttest

\begin{tabular}{|c|c|c|c|c|}
\hline \multirow{2}{*}{ Statistik } & \multicolumn{2}{|c|}{ Eksperimen } & \multicolumn{2}{c|}{ Kontrol } \\
\cline { 2 - 5 } & Pretest & Posttest & Pretest & Posttest \\
\hline $\mathrm{N}$ & 34 & 34 & 34 & 34 \\
\hline$\overline{\mathrm{X}}$ & 44,58 & 81,29 & 48,47 & 64,70 \\
\hline $\mathrm{S}$ & 12,34 & 7,67 & 10,22 & 7,06 \\
\hline $\mathrm{L}_{\mathrm{o}}$ & 0,1403 & 0,1163 & 0,1405 & 0,1427 \\
\hline $\mathrm{L}_{\text {tabel }}$ & 0,1519 & 0,1519 & 0,1519 & 0,1519 \\
\hline Kesimpulan & Normal & Normal & Normal & Normal \\
\hline
\end{tabular}

Berdasarkan tabel 1.2, hasil uji normalitas untuk data pretest dan posttest dilakukan pada taraf signifikansi 95\% $(\alpha=0,05)$ dengan menggunakan tabel nilai kritis uji Liliefors, yaitu nilai $\mathrm{L}_{\text {tabel }}$ dengan $\mathrm{n}=34$ adalah 0,1519 untuk kedua sampel penelitian. Dari kedua data tersebut dapat disimpulkan bahwa hasil pretest dan posttest kedua kelompok eksperimen dan kontrol berdistribusi normal karena memenuhi kriteria $\mathrm{L}_{0}<\mathrm{L}_{\text {tabel. }}$.

Tabel 3

Hasil Uji HomogenitasPretest-Posttest

\begin{tabular}{|c|c|c|c|c|}
\hline \multirow{2}{*}{ Statistik } & \multicolumn{2}{|c|}{ Pretest } & \multicolumn{2}{c|}{ Posttest } \\
\cline { 2 - 5 } & Eksperimen & Kontrol & Eksperimen & Kontrol \\
\hline$S^{2}$ & 152,37 & 104,5 & 58,88 & 49,91 \\
\hline$F_{\text {hitung }}$ & & 1,45 & \multicolumn{2}{c|}{1,18} \\
\hline$F_{\text {tabel }}$ & \multicolumn{2}{|c|}{1,79} & \multicolumn{2}{c|}{1,79} \\
\hline Kesimpulan & \multicolumn{2}{|c|}{ Homogen } & \multicolumn{2}{c|}{ Homogen } \\
\hline
\end{tabular}

Berdasarkan tabel 1.3, hasil uji homogenitas untuk data pretest didapat $\mathrm{F}_{\text {hitung }}=$ 1,45 dan data posttest didapat $F_{\text {hitung }}=1,18$. Dengan taraf signifikan $95 \%(\alpha=0,05)$ dengan derajat kebebasan $\left(\mathrm{dk}_{1}\right)=33$ dan $\left(\mathrm{dk}_{2}\right)=33$ didapat $\mathrm{F}_{\text {tabel }}=1,79$. Dari kedua data tersebut 
dapat disimpulkan bahwa data hasil belajar darikeduasampel tersebut mempunyai varians yang sama atau homogen karena memenuhi kriteria $\mathrm{F}_{\text {hitung }}<\mathrm{F}_{\text {tabel. }}$.

Tabel 4

Hasil Perhitungan Uji Hipotesis

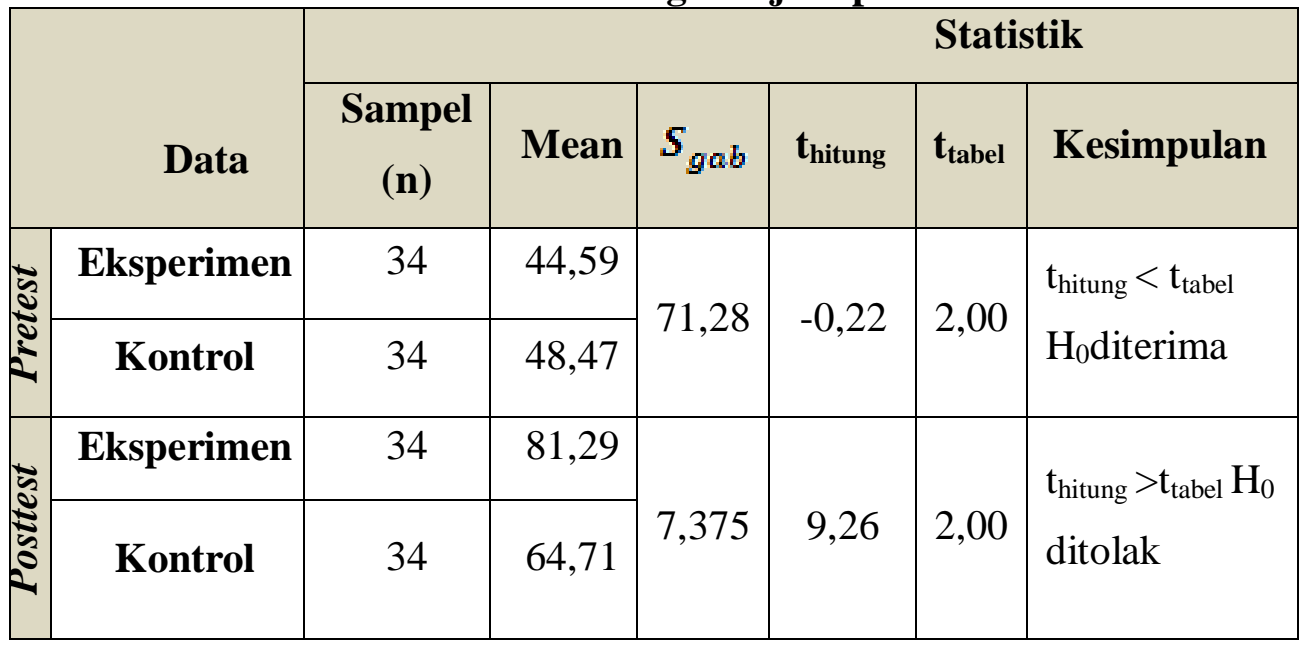

Dari tabel 4 hasil perhitungan uji hipotesis di atas,nilai pretest kelas eksperimen dan kelas kontrol pada taraf signifikansi $\alpha=0,05$ diperoleh $t_{\text {hitung pretest sebesar }-0,22}$ dengan $t_{\text {tabel }} 2,00$, maka dapat dilihat bahwa hasil thitungpretest lebih kecil dibandingkan dengan $t_{\text {tabel. }}$ Berdasarkan kriteria pengujian yang telah ditetapkan, yaitu: jikat ${ }_{h i t u n g}<t_{\text {tabel, }}$, maka $\mathrm{H}_{\mathrm{o}}$ diterima dan dapat dinyatakan bahwa tidakterdapat pengaruh pendekatan lingkungan terhadap hasil belajar siswa. Dengan demikian, kedua kelas tersebut layak dijadikan sampel penelitian.

Untuk nilai postest kelas eksperimen dan kelas kontrol pada taraf signifikansi $\alpha=$ 0,05diperoleh thitungposttest sebesar 9,26 dengan $t_{\text {tabel }}$ 2,00, maka dapat dilihat bahwa hasil

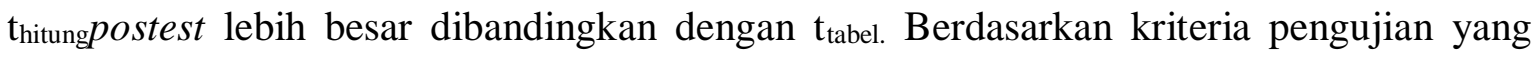
telah ditetapkan, yaitu: jika $t_{\text {hitung }}>\mathrm{t}_{\text {tabel, }}$ maka $\mathrm{H}_{\mathrm{a}}$ diterima, dan dapat dinyatakan bahwa terdapat pengaruh pendekatan lingkungan verifikasi terhadap hasil belajar siswa. Dari hasil posttest $_{s}$ rata-rata hasil belajar siswa kelompok eksperimen lebih tinggi daripada rata-rata hasil belajar kelas kontrol. 


\section{KESIMPULAN}

Berdasarkan hasil penelitian dan pembahasan yang telah dikemukakan pada bab sebelumnya, maka dapat disimpulkan bahwa PendekatanLingkungan memberikan pengaruh yang signifikan terhadap hasil belajar IPA siswa kelas V pada materi Benda dan Sifatnya. Hal ini dapat dilihat dari hasil perhitungan uji-t untuk data posttest diperoleh nilai $t_{\text {hitung }}>t_{\text {tabel }}$ yaitu sebesar 9,26>2,00. Jadi dapat dinyatakan bahwa hipotesis Ha diterima dan Ho ditolak. Selain itu, dapat dilihat juga pada kelas eksperimen mengalami kenaikan yang signifikan disetiap jenjang kognitifnya $\left(\mathrm{C}_{1}, \mathrm{C}_{2}, \mathrm{C}_{3}\right)$, yaitu 32,68 untuk $\mathrm{C}_{1}, 41,92$ untuk $\mathrm{C}_{2}$, dan 36,03 untukC $\mathrm{C}_{3}$.

\section{DAFTAR PUSTAKA}

Arikunto, Suharsimi. 2010. Prosedur Penelitian Suatu Pendekatan Praktek, Cet. Ke14Jakarta: Rineka Cipta.

---------. 2007. Dasar-Dasar Evaluasi Pendidikan. Jakarta: Bumi Aksara.

Basyirudin, Usman. 2002. Metodologi Pembelajaran Agama Islam, Jakarta: CiputatPers.

Devi, Poppy Kamalia. 2013. Keterampilan Proses dalam Pembelajaran IPA untuk Guru SMP, Modul diakses dari: http://www.p4tkipa.net/modul/Tahun2010/BERMUTU/MGMP/Keterampilan\%20Pr oses\%20dalam\%20Pembelajaran\%20IPA.pdf pada tanggal 01 Februari2013.

Djamarah, Syaiful Bahri dan Aswan Zain. 1996. Strategi Belajar-Mengajar. Jakarta: PT. Rineka Cipta.

Fathurrohman, Pupuh dan M. Sobry Sutikno. 2007.Strategi Belajar Mengajar. Bandung: PT. Refika Aditama.

Hernawan, Asep Herry, dkk.Belajar Dan Pembelajaran SD. Bandung: UPI PRESS

Ikhsan, Fuad. 2001. Dasar-dasar Kependidikan, Jakarta: PT.Rineka Cipta.

Iskandarwassid dan Dadang Sunendar. 2011. Strategi Pembelajaran Bahasa, Bandung:PT. Remaja Rosdakarya.

Nasution, Noehi. 2005. Pendidikan IPA di SD. Jakarta: Universitas Terbuka.

Purwanto. 2011. Evaluasi Hasil Belajar. Yogyakarta: Pustaka Belajar.

Roestiyah dan Yumiati Suharto. 1985. Strategi Belajar Mengajar. Jakarta: Bina Aksara.

Rustaman, Nuryani, dkk. 2007. Strategi Pembelajaran Biologi. Jakarta: Universitas Terbuka.

Samatowa, Usman. 2010. Pembelajaran IPA Di Sekolah Dasar. Jakarta: PT.Indeks.

Sobur, Alex. 2003. Psikologi Umum, Bandung: CV.Pustaka Setia. 
Sudijono,Anas. 2011. Pengantar Evaluasi Pendidikan, Cet.11, Jakarta: PT. RajaGrafindoPersada.

Sudjana. 2005. Metoda Statistika.Bandung: Tarsito.

Sudjana, Nana. 2008. Penilaian Hasil Proses Belajar Mengajar.Bandung: PT. Remaja Rosdakarya.

dan Ibrahim. 1989.Penelitian dan Penilaian Pendidikan. Bandung: CV. Sinar Baru.

Sukardi. 2011.Evaluasi Pendidikan: Prinsip dan Operasionalnya.Jakarta: Bumi Aksara.

Supardi. 2012.Aplikasi Statistika dalam Penelitian. Jakarta: Ufuk Press.

Suprianti, Dhia. 2013. Penggunaan Metode Eksperimen Dalam Pembelajaran IPA diakses dari http://dhiasuprianti.wordpress.com/penggunaan-metode- eksperimen-dalampembelajaran-ipa/ pada tanggal 03 Feb 2013.

Syah, Muhibbin. 2010. Psikologi Pendidikan Dengan Pendekatan

Baru, Bandung: PT. Remaja Rosdakarya. . 2010. Psikologi Pendidikan Dengan Pendekatan Baru. Bandung: PT. Remaja Rosdakarya.

Widodo, Ari, dkk. 2007. Pendidikan IPA Di SD.Bandung: UPI PRESS.

Winataputra,Udin S. 2005. Strategi Belajar Mengajar. Jakarta: Universitas Terbuka. Yamin,Martinis. 2010. Kiat Membelajarkan Siswa. Jakarta: Gaung Persada Press.

Zulfiani,dkk. 2009. Strategi Pembelajaran Sains, Jakarta: Lembaga Penelitian UINSyarif Hidayatullah Jakarta. 